\title{
Towards Building Academic Entrepreneurial Programs at Saudi Universities: Predicting Future Jobs in Light of the NEOM Project
}

\author{
Ghadi O. Alghamdi ${ }^{1} \&$ Azala M. Alghamdi ${ }^{2, *}$ \\ ${ }^{1}$ Public Education, Al Baha, KSA \\ ${ }^{2}$ Education College, Albaha University, KSA \\ *Correspondence: Educational Administration and Planning Department, Education College, Albaha University, Al \\ Baha, zip 65411, KSA. Tel: 966-500-035-177. E-mail: dr.azalaalghamdi@yahoo.com
}

Received: July 11, 2020

Accepted: August 10, 2020

Online Published: August 17, 2020

doi:10.5430/wje.v10n4p60

URL: https://doi.org/10.5430/wje.v10n4p60

\begin{abstract}
The purpose of the current study was to examine the type and form of future jobs, in light of the modern technological trends of the NEOM project. To achieve its objectives, the study utilized descriptive statistics with the Delphi method. The researchers convened a sample of ten experts in the fields of Science and Technology, Human Resources Planning, and Educational Administration and Planning, who participated in three scientific rounds. The findings from these rounds provide a suggested model for future jobs in the Kingdom of Saudi Arabia, in light of the modern technological trends of the NEOM project. This proposed model consists of twenty types of future jobs expected to achieve high degrees of importance over the next decade. Examining the study hypothesis yielded no statistically significant differences at the level $(\alpha \leq 0.05)$ between the second and third scientific-round averages, confirming the stability of the experts' responses and their approval of this list of future jobs. The study recommends directing Saudi universities to develop academic programs to meet the needs of the NEOM project in the disciplines of Mechatronics Engineering, Using Technology in Surgery, and Software Engineering. Building academic programs with specific learning outcomes will ensure that graduates can acquire the necessary entrepreneurial skills, especially in disciplines such as Computerized Quantity Encrypted Engineering, Virtual Reality Technologies Design, and Three-Dimensional Printing Specialization. These programs will reduce acceptance of traditional academic programs that do not match the future requirements of the labor market, the Saudi 2030 Vision initiatives, and projects such as the NEOM project. The benefit from seats in more closely related programs will include the development of all programs in various universities and colleges to be entrepreneurial, supporting the new and expected technical trends in the labor market and all promising sectors of investment, such as the NEOM project.
\end{abstract}

Keywords: Saudi Universities, future jobs, NEOM project, academic entrepreneurial programs

\section{Introduction}

"Yes, no doubt; human resource development is a fundamental part of this strategic plan. First, we must pay tribute to all Saudis. We have a fascinating, incredible, and honorable Saudi mentality, especially in the younger generation ... powerful and courageous energy, high culture, strong professionalism ... only work left."

With this encouraging statement, the ambitious young leader Crown Prince Mohammad bin Salman (MBS) praises young Saudis. MBS confidently stresses that they are the cornerstone of achieving the National Vision of Saudi Arabia 2030 and that the country will adopt them and invest in their capabilities. This reflects the belief that the main driver in advancing development and realizing the ambitious vision is an optimal investment in human capital, the total stock of knowledge and skills that individuals possess (PwC, 2020; Ugal \& Betiang, 2009).

The National Vision 2030 focuses heavily on investing in the capabilities and potential of ambitious Saudi youth. It emphasizes the large proportion of youth eager to use modern technology, one of the pillars of the ambitious vision of the Saudi Press Agency (2016). This passion opens new, wide horizons, as the modern technological revolution has no limits and no end. Developed countries are making progress by applying technology in all spheres of life (Bostorm, 2007; Wellener \& Manolian, 2020). Therefore, the new technology revolution is a cornerstone of the 
Kingdom's vision. A study by Dell EMC, which included $75 \%$ of Saudi business leaders, cited $46 \%$ of that total who said that the Saudi Vision 2030 would create new job opportunities, based primarily on the modern technological revolution and information technology. The Kingdom's Vision 2030 programs will generate more than 3 million jobs. Following is an estimated distribution of the number of jobs in the Kingdom's most prominent Vision 2030 programs (Riyadh Economic Forum, 2020).

- National Industrial Development and Logistics Program with 1,600,000 jobs.

- Housing Program with 469,000 jobs.

- Doyof Al Rahman Program with 360,000 jobs.

- National Transformation Program 450,000 jobs.

- Public Investment Fund program with 285,000 jobs.

- Quality of Life Program with 346,000 jobs.

In a similar context, Brain (2013) notes that the rapid development of computer technology would bring smart robots to the United States economy by 2030 , and these robots will acquire about $50 \%$ of U.S. jobs over a decade or two, which will result in approximately 50 million unemployed individuals in America alone. Despite the considerable anxiety regarding the potential for jobs disappearing due to technology, others appear, and employment generally rises (OECD, 2019). A few months later, the NEOM project, "Investing in the Future," was launched to support and achieve the directions of Saudi Vision 2030. In addition, the ambitious leader, His Highness Prince Mohammed bin Salman, confirmed it by saying, "The Saudi youth is the pillar of NEOM," pointing out that $70 \%$ of the Saudi people are under the age of thirty years. MBS also indicated that the Saudi human, distinguished by wit and tremendous determination, is the essential element in the NEOM project, considering NEOM as the location of dreamers in a distinguished world and indispensable to the various energy sources, as it aims for more robots than humans.

Despite recent technological developments, the next phase will be more developed and advanced, in a way that exceeds imagination, especially in the employment of modern technologies in the sectors of energy and water, transportation, biotechnology, food and medicine, technical and digital sciences, advanced manufacturing, media and media production, entertainment, and living, the NEOM project target sectors. As an inevitable result of these tremendous technological developments, Kaeser (2017) indicated during the first meeting of the "Investing in the Future Initiative" that millions of jobs will fade, in exchange for creating other new jobs. The President of the International Monetary Fund (IMF) Christine Lagarde confirmed this during her speech at the first meeting of the Future Investment Forum, saying that the world today is on the verge of fundamental changes in future jobs, and that new jobs will be invented for about two-thirds of children in schools today around the world (Lagarde, 2017). For instance (and not limited to this instance), the robots in the NEOM region will reduce the human workforce's role in heavy work and increase the presence of a highly skilled workforce, such as doctors and professionals of similar ability (Future Investment Initiative, 2017). Therefore, universities and research centers in developed countries play the primary role in modernizing various aspects of life and absorbing all the changes of the age. So, institutions of higher education must prepare to keep up with the different modifications by building creative minds that undertake to create and develop modern technologies capable of contributing to industrial and economic progress, providing quality investment opportunities, and facilitating cognitive enrichment. Undoubtedly, they will complete the path toward building highly skilled human resources. Pistono (2012) confirms that robots will steal jobs from us, as the total number of posts most sectors require will gradually decrease over time. Yet, new occupations must be found for those newly displaced due to automation, as this is hard and requires much study and research.

Policies and the future of jobs require immediate action; otherwise, disparities in the labor market will increase (OECD, 2019). Planning and predicting future careers are an imperative necessity that global changes in all fields, especially in technical areas, have accelerated. The aspirations for the future impose seeking in the direction of the Saudi Vision 2030, which is moving steadily and powerfully toward a leading global country on all fronts. Such predictions benefit not only guiding government-policy planning but also directing the decisions of business people, universities, and research centers, as well as helping families to choose the best education for their children (International Experts and Local Economic Development Agencies [ILS LEDA], 2013).

Accordingly, overcoming all obstacles and creating all conditions to direct research projects, academic disciplines, and programs toward strategic options for the coming period have become crucial for all sectors, including universities. Thus, this study that aims to develop a future vision for jobs in the Kingdom of Saudi Arabia, in light of the new technical direction of the NEOM project, has emerged, through monitoring future expectations of experts in science and technology, human resources, educational administration, and planning, using the Delphi method to 
predict the future jobs.

\section{Purpose of the Study}

The purpose of the current study is to determine the type and shape of future jobs in the Kingdom of Saudi Arabia, considering the new technical direction of the NEOM project and based on the experts' expectations of the present study.

\section{Research Problem}

The Kingdom of Saudi Arabia stands today on the threshold of a new development era that differs from the past, in terms of content and goals. These are fundamental changes, launched within the framework of the Kingdom's Vision 2030, which aims to reserve the appropriate place for the Kingdom and its people in the future as an entrepreneurial country in various fields. The vision creator MBS, through this vision, aims to build the model of a world leader in all areas, and his planned endeavor toward establishing a unique technical structure is one of the promising directions that contribute to achieving his aspirations. Within this framework, the NEOM project was launched to represent a new and unconventional turn in all its dimensions, providing quality and progressive technical life that attracts creative and dreaming minds in a developed and different world. All these changes put Saudi universities to the test and require reading the future and working in its light to build an innovative generation that possesses the skills of future jobs, to achieve the vision of their homeland.

Prediction of future jobs is a crucial process, to prevent disparities among workers in large segments and help them benefit from the available opportunities the economy generates in the future (OECD, 2019). On the other hand, failure to plan and predict future jobs will increase the rate of unemployment, social cleavages, and growing discontent, which could harm productivity, growth, well-being, and social cohesion (OECD, 2019). Pompa (2015) stresses that the best way to eliminate these challenges is seriously engaging in cross-sector collaboration. Policymakers, academics, stakeholders, business leaders, employees, and students themselves all must cooperate toward positive results (Pompa, 2015). If future jobs are not predicted, the potential risk is a mismatch between education outcomes and the needs of the labor market, delayed economic development, and the inability to compete locally and internationally (Riyadh Economic Forum, 2020). According to the results of many previous studies (Alzahrani, 2018; Aref, Hegazy \& Abdel-Hamid, 2108; Al-Damanhoury, 2013; Maiman, 2012), a gap exists between higher education outcomes and the needs of the labor market. As the outputs of higher education do not match the needs of the labor market at present, it is necessary to review and update the academic programs in higher education until the unemployment rate decreases and these outputs are compatible with the requirements of the Saudi labor market.

As stated by the McKinsey Global Institute (2018), 41\% of the jobs in Saudi Arabia are at risk of replacement. Therefore, the need to plan future employment, in light of the initiatives that aim to achieve the national Vision 2030 and expedite the implementation of the plans and programs, is essential to simultaneously reach a suitable quantity and quality. Therefore, the current study determines the future jobs that Saudi universities must consider, to develop and build their academic programs in line with future trends in general and the NEOM project in particular.

\section{Research Questions}

The main questions of the current study are:

RQ1: In light of the modern technological trends of the NEOM project, what are the future jobs that define learning outcomes for academic programs at Saudi universities?

RQ2: Is there a statistically significant difference $(\alpha \leq 0.05)$ among experts' perceptions of their appreciation of the importance of future jobs, in light of the recent technical direction of the NEOM project, between the averages of future jobs in the second and third scientific rounds?

\section{Significance of the Study}

The current study synchronizes its approach with the modern technology revolution, predictions for developments in the next decade, and the interest of the Kingdom of Saudi Arabia leadership in building a pioneering model country in all fields. These require such a study to predict future jobs in light of these developments. This study might contribute to highlighting the anticipated role of Saudi universities in creating entrepreneurial programs to generate talents who possess high skills and creativity, in line with the technologies of the NEOM project, as one of the 
significant pioneering initiatives of its various aspects and regarding future jobs in general. The outcomes of this study may clarify the vision for leaders at Saudi universities about future careers related to recent technological developments, in the absence of or ignoring predictive studies of this aspect. The lack of such studies entails much waste of all resources at the country level and fails to direct the various sectors (primarily educational) toward the right direction for the future, in the way of linking its outputs to future nontraditional labor markets.

\section{Study Terminologies}

\subsection{Academic Entrepreneurial Programs}

The academic entrepreneurial program is designed in an entrepreneurial way that enables students to be more proactive, innovative, and visionary, and to take calculated risks.

\subsection{Future Job}

The future job is a vision resulting from prediction based on experts' perspectives on the jobs of the next decade, in terms of specializations and skills in the context of the modern technology trends of the NEOM project.

\subsection{NEOM Project}

The NEOM Project occupies a unique region extending across three countries (Asia, Europe, Africa), including a new vital destination in the northwest part of the Kingdom, seeking to become a hub for bringing the best minds and companies together to overcome the limits of innovation on the highest levels of human civilization. This particular region aims to outperform the major global cities, in terms of competitiveness and lifestyle; it is expected to become the center of the whole world.

\section{Literature Review}

\subsection{Building Academic Entrepreneurial Programs}

Entrepreneurship plays a significant role in creating future jobs and improving economic strength in the job market and the economy as a whole (Byun, Sung, Park, \& Choi, 2018). Academic programs in their traditional form no longer meet future needs nor qualify students for the job market. Jobs of the future require a set of entrepreneurial skills (He et al. 2017), such as resilience, vision, passion, integrity, self-confidence, ability to motivate, sociability, and flexibility. Therefore, universities must build academic programs using an entrepreneurial method to equip students with the entrepreneurial characteristics the labor market requires, to facilitate their obtaining the best jobs in the future. Walter and Block (2016) mention a noticeable increase in universities' interest in entrepreneurship education; entrepreneurship programs have expanded to prepare pupils who believe in the future importance of entrepreneurship to become future entrepreneurs. This interest has also increased in all degree programs, from elementary schools to graduate schools, to enhance the entrepreneurial spirit (Byun, Sung, Park, \& Choi, 2018). Moreover, Valerio, Parton, and Robb (2014) emphasize that entrepreneurship education training is an established field of study that attracts the attention of policy makers and students.

Building academic entrepreneurial programs is an essential strategy for all universities, particularly in competitive and turbulent environments. Such programs help individuals to overcome potential challenges, motivating them toward innovation and initiative, and away from following the traditional methods of searching for jobs. In other words, they will be job creators instead of job seekers (Xi, Block, Lasch, Robert, \& Thurik, 2018).

Regarding entrepreneurial programs in higher education, Valerio, Parton, and Robb (2014), in cooperation with The World Bank, conducted a study about entrepreneurship education and training programs in higher education. This study identifies and examines a total of ten entrepreneurship-education programs targeted at university students. The results indicate a relationship between entrepreneurship outcomes and academically focused entrepreneurship education training interventions, underscoring the importance of such training. It entrepreneurially builds academic programs at universities so that more entrepreneurial leaders will emerge who can adapt and fulfill the requirements of the labor market.

\subsection{Technical Developments and Future Job}

Relying mainly on the use of technology instead of labor, the Fourth Industrial Revolution has swept the various walks of economic, legal, educational, and social life, where smart automation and robotics are the next workforces. It is distinguished from previous revolutions by a set of new technologies that combine the physical, digital, and biological worlds that affect all disciplines, economies, industries, and even difficult ideas about what it means to be human (Schwab, 2017). Therefore, keeping abreast of these modern technological developments is vital, an urgent 
necessity that must accompany various fields that make the most of them (Xu, David, \& Kim, 2018). These technologies include solar energy, 3D printing, virtual reality technologies, brain readers, external support structures, monitoring devices for various body activities, quantum computing, fusion energy, naked eye masking, and floating building technology. In light of this rapid technological advancement, the question arises of what the jobs of the future will be in the coming decades, amid such rapid development. This question remains and attracts the attention of many planners, experts, and specialists.

\subsection{The Concept of Technical Developments}

The dynamic nature of technology contributes to the emergence of different definitions and concepts, where no specific definition exists but depends on the field or the specialization in which the technology appears, and its definition differs depending on the authors and the context of the disciplines (Lan \& Young, 1996). Defining technology can begin by referring to the origin of the word "technology," as translated into Arabic from Greek techno, which means technical skill, while -logy means studying by organizing technical skills (Alzamely, 2012). Kumar et al. (1999) define technology as consisting of two main components: the physical component, containing such elements as products, tools, equipment, diagrams, technologies, and other processes, and the informational component, consisting of experience in management, marketing, production, quality control, reliability, and skilled human resources.

\subsection{Technical Developments and Its Impact on Future Jobs}

Nowadays, the topic of technical developments and their impact on future jobs is one of the main issues that concern individuals, particularly young people, who wonder whether modern technology can take away their jobs or create new jobs for them instead. A study by the International Labor Organization [ILO] indicates that nearly $40 \%$ of young people around the world express concern about job opportunities available to them in the future, with modern technological developments. There is no clear strategy on this matter; $56 \%$ of current workers in the countries of the Association of Southeast Asian Nations [ASEAN] alone face a high risk of losing their jobs, especially those that can be automated (ILO, 2016). Pistono (2012) confirms that in the future, robots will steal our jobs and the total number of careers required in most sectors will decrease gradually. So, finding new careers for those newly displaced due to automation is tremendously hard and requires much study and research to discover a set of future jobs.

On the other hand, the (ILO, 2016) indicates two types of jobs. First, the anti-automation jobs, or non-routine tasks, such as doctors, lawyers, and managers perform, require judgment, problem-solving, intuition, persuasion, and creativity. Second, the routine jobs, such as those related to money exchange, printing, and machine operation, cannot resist automation. As a result, the McKinsey Global Institute emphasizes that it is crucial to adapt to the coming era of automation, which relies heavily on robots and computers, to not only perform physical work but also carry out activities that involve mental capabilities, with high efficiency (MGI, 2017). Overall, the sectors of greatest demand will undoubtedly be high tech and the green economy, as well as the traditional personal-care sector for the aging population (ILS LEDA, 2013).

\subsection{Saudi Arabia Vision 2030 and the NEOM project}

The Kingdom of Saudi Arabia has observed numerous rapid and daring changes and developments, of which only confident and distinguished leadership is capable. Once assuming his multiple responsibilities, the Crown Prince Mohammed bin Salman bin Abdulaziz announced in 2016, with confidence and ambition, the vision of the Kingdom of Saudi Arabia 2030. This vision is the most significant historical event the Kingdom has witnessed since the discovery of oil in 1938, an explicit declaration ending the prolonged oil addiction of the Saudi economy (Al-Mohandes, 2016). In only a year, the dream NEOM project was launched, explicitly demonstrating the Kingdom's Vision 2030 becoming reality. From this point, the citizens of Saudi Arabia, the younger of them before the elderly, felt a unique world coming, full of development, progress, and prosperity, which meets the intense desires and aspirations. Following is a brief explanation of the National Vision 2030 of the Kingdom of Saudi Arabia, as well as the dream NEOM project.

\subsubsection{Saudi Arabia Vision 2030}

Summarizing the vision of the Kingdom of Saudi Arabia 2030 in limited lines is difficult, due to numerous projects and initiatives that this vision includes and the in-depth, forward-looking outlook for the future, which fundamentally depends on unlimited ambition. The Saudi Vision 2030 expresses an ambitious strategic plan for the most substantial economic and social event in the history of the Kingdom of Saudi Arabia, through the establishment of a giant sovereign fund exceeding more than $\$ 2$ trillion, to purchase the four largest international companies, Apple, Microsoft, Google, and Berkshire Hathaway (Al-Mohandes, 2016). Establishing the giant sovereign fund indicates 
the Kingdom's investment capacity and its strong orientation toward diversification of its economy, especially concerning the military, mining, minerals, and various investments (Al-Mohandes, 2016). In general, the Saudi Vision 2030 focuses on the depth of the Kingdom of Saudi, Arab and Islamic, along with its pioneering investment power and linking the three continents in three main aspects (Saudi Press Agency, 2016), as follows.

- The Vital Society: Society is the basis for launching the Kingdom of Saudi Arabia's 2030 vision to achieve economic prosperity. This aspect derives its importance from the Kingdom's belief in the significance of building a vital society. Its members utilize the moderation methodology in the Islamic religion, in addition to their pride in their patriotism and their ancient cultural heritage, all within a positive and supportive environment in which all avenues of life are available to all.

- The Thriving Economy: This field focuses on building an effective educational system, linked to the needs of the labor market by providing opportunities for everyone, from entrepreneurs and small enterprises to large companies, to diversify the economy and create job opportunities for citizens. Based on the fact that competitiveness plays a significant role in raising the quality of services and economic development, this field also focuses heavily on the allocation of government services and improving the business environment. Thus, attracting the best talents will contribute to exploiting the unique strategic location of the Kingdom of Saudi Arabia with high efficiency.

- The Ambitious Nation: The essential feature of this domain is to promote the high ambition of the homeland in its production and achievements at the local and global levels, in terms of focusing on effectiveness and responsibility and their application at all levels. Accordingly, this scope concentrates comprehensively on the public sector by creating an appropriate environment for citizens, the business sector, and the nonprofit sector, taking the initiative and responsibility for facing future challenges, and seizing available opportunities. Developments in the Kingdom of Saudi Arabia dramatically increase as several current projects emerge in our country day after day. These projects are evidence of the process of the Kingdom's 2030 vision, which mostly focuses on moving the Kingdom from an economy that relies heavily on oil revenues, to reducing this dependence through diversification of income sources and creating new sources of financing to reduce the institutions' reliance on the government's support. An example of such megaprojects is the NEOM project, the largest Saudi project linking three countries. The Saudi Vision 2030 focuses on this link, as the Kingdom of Saudi Arabia links the three continents.

\subsubsection{NEOM Project}

In pursuit of the ambitious vision of the Kingdom of 2030, which aims to make the Kingdom of Saudi Arabia an entrepreneurial global model in various aspects of life and a link among the three continents, the Prince Mohammed bin Salman bin Abdulaziz Al Saud, Saudi Crown Prince and Deputy Prime Minister of The Public Investment Fund Board, launched the massive NEOM project, embodying and translating Vision 2030 into reality. So, what does NEOM mean? The naming of the "NEOM project" raised the curiosity of researchers and experts about the reason for choosing this name. Explanations and definitions abounded until MBS announced the meaning of the word "NEOM" by dividing it into two parts. The first three letters $(N E O)$ in Latin mean the word "new," and the fourth letter (M) and in Arabic refers to the word "Mostaqbal," which means "the future." The term (NEOM) means "the new future." It is the city of the future, dream, and science fiction, which depends on the use of advanced technology in various sectors. The NEOM project is an exceptional project of its kind; it connects three continents and seeks to be a gathering point for the best minds and companies that combine to cross the boundaries of innovation, to the highest levels of human civilization. This particular region is designed to become a leading center for the entire world (Al Barqawi, 2017).

Since the NEOM project focuses on investing in nine major sectors, the next part presents the findings of previous studies regarding the impact of technology on the future of jobs in these nine sectors.

- Energy and Water Sector: Modern technology is a factor that impacts the energy and water sector, as well as future jobs related to this sector. According to the results that the "Voice of Manpower" presented at the Water Industry Asset Management Conference in 2017, the modern workers in the energy and water sector face a significant challenge because more than $80 \%$ of workers in the water sector lack skills. Besides, technological development is expected to create more jobs in renewable energy, as the employment number will triple to 24 million by 2030 (Smith, 2017).

- Mobility Sector: New technology will have a significant impact on the mobility sector, increasing the number of jobs in such industries as mobility and communications technology. The mobility industry is also likely to lead significant growth in transportation and logistics roles, as it plays its traditional role in linking countries and industries (Employment Trends, 2017). Consequently, this sector will change its priority from a product focus to a 
service focus, creating many new offers (DU Press, 2017).

- Biotech Sector: According to the report by James C. Greenwood, President and CEO of the Biotechnology Innovation Organization (BIO), at the National Bioscience Report Shows Industry Creating Jobs and Driving Innovation (BIO, 2017), the development and modernization of technology will increase jobs, particularly in the biotechnology sector. This has considerable impact on creating new, high-paying jobs expected to emerge due to innovative approaches. For instance, from 2012 to 2014, 35 U.S. states experienced net growth in biological-science jobs. Therefore, the biotechnology sector will not stop providing more high-paying jobs (BIO, 2017).

- Food Sector: The utilization of advanced technology has become fundamentally important for the food sector, as mobile devices have appeared on the table and in online reservations, social media, and new payment methods (Vardy, 2017). Currently, some restaurants use robots rather than labor to provide food, as these modern technologies save money. Thus, the tendency toward automated manufacturing began, with manufacturing industries witnessing a $10 \%$ to $20 \%$ increase in production, but a contrasting $2 \%$ to $5 \%$ increase in jobs (West, 2017).

- Advanced Manufacturing Sector: There are more new jobs in the advanced manufacturing sector, coinciding with recent technological developments. For instance, a study by the National Association of Manufacturers in the United States of America revealed that $80 \%$ of manufacturers have many jobs ahead, in the field of advanced manufacturing; however, finding qualified workers is a massive concern for them (Crawford, 2017).

- Media and Media Production: Due to the development of modern technologies, some jobs in the media and media-production sector are beginning to fade. For instance, sound technicians no longer need to fix sound or lighting, and an automatic desktop setup operated by only one person can replace the entire TV studio (Acker, 2015).

- Entertainment Sector: With the entry of the Internet and the development of modern technologies, the entertainment sector has witnessed enormous growth. As a result, the media, entertainment, and information industry expects higher employment in the arts, design, entertainment, sports, and media, along 1with high growth in the field of computers and mathematics. Indeed, the digital transformation of the world fully affects the entertainment sector, as individuals tend to prefer home entertainment (e.g., watching TV, video games) to any outside entertainment, creating demand for technical professionals, support assistants and managers, and other technical jobs (Employment Trends, 2017).

- Technological and Digital Sciences Sector: The prospects for career opportunities for graduates from colleges of technology and digital sciences are bright and promising, as young professionals in this field will find great job opportunities in various sectors. Also expected are the technological and digital sciences that will develop at a rapid pace within a decade, providing professionals in this field with approximately 485,000 high-wage jobs. These jobs include but are not limited to web developers, interactivity designers, network administrators, architects, computer systems analysts, and IT managers (Kent State University, 2017).

- Living as a Foundation Sector: The technological age brings significant changes and opens new opportunities. The world has dramatically changed, and it is time to deal with these changes efficiently and effectively - for highly skilled professionals, who deal with technology every day, who develop themselves and their homeland and move forward, with every desire and confidence to build a better future. It is impossible today to imagine the workplace without a computer or some other digital device. Therefore, NEOM has launched an extraordinary idea and a dream project that brings together creators who will be a fundamental pillar for the rest of the sectors mentioned above, by focusing on modern technology that can change by eliminating some jobs, creating new and unusual positions, and developing essential areas of the global economy.

\section{Previous Studies}

This section reports previous studies related to the current research, followed by comments. It discusses aspects of agreement and difference by highlighting the addition of the present study and distinguishing it from those previous studies.

The McKinsey Global Institute (2019) study entitled "The Future of Work in America: People and Places, Today and Tomorrow." While much of the research focuses on job displacement due to automation, this study examines the national numbers to explore present and potential future jobs for people and places across America, analyzing 315 cities and more than 3,000 counties. Most dynamic counties have high-growth industries, while rural ones have higher unemployment and lower educational attainment. This study concludes that automation will have an impact on future jobs. For instance, it will displace many workers, such as people in office support, food service, transportation and logistics, and customer-service roles. On the other hand, the economy will generate jobs, 
especially positions in healthcare, STEM fields, and business services, along with work demanding personal interaction. This study recommends that communities prepare for dramatic changes by supporting workers in such transformations, focusing on job matching and mobility, skills and training, economic development, and job creation.

The Future Foresight Foundation (2019) performed a study entitled "Future Jobs 2040" that aims to predict future jobs (by the year 2040) for current children and grandchildren. The study concludes that although technology will control many jobs, in turn, it will produce many as well. Among the most important fields of these jobs are those related to Big Data, drones' private crews, and experts in personal health, artificial intelligence, self-driving, blockchain technology, 3D printing, cryptocurrency, engineering, sensor systems, space mining, and genomics.

The McKinsey Global Institute (2017) performed a study entitled "Technology, Jobs, and the Future of Work," which lasted for two years of research, in which many specialists, experts, and researchers from the United States of America and the United Kingdom participated. The aim was to study the impact of technology on the business sector and society, especially regarding the future of work and the potential effects on the global economy of data, automation, robotics, and artificial intelligence. The study reached many results, perhaps the most important of which are the following.

- The "future of work" must adapt to the new era of automation, which depends on robots and computers that not only perform physical work activities but also carry out activities that include mental capabilities, with high efficiency.

- Automation will considerably affect several sectors in many countries, such as China, India, Japan, and the United States of America. The sectoral mix and mix of activities within the sectors in these countries will affect automation capabilities. For example, such industries as manufacturing and agriculture include physical activities that can be automated.

- Automation will not happen overnight, but five main factors will affect its approval and adoption. For example, the technical feasibility, the cost of developing and deploying solutions, labor-market dynamics, economic benefits, and organizational and social acceptance will critically influence the adoption of automation in all sectors. However, we must consider that it will take decades to fully automate activities.

The Social Market (2016) also conducted a study entitled "Future Jobs." The study aims to reveal the number of jobs expected to open between 2016 and 2023 and how science, research, engineering, and technology will contribute to the number of these jobs. Overall, this study concludes with the following findings:

- Jobs in science, research, engineering, and technology will rise by $3 \%$ to $6 \%$, double the rate of other jobs, from now until 2030. The report attributes this growth to investment in infrastructure, digital, and innovation, expected to create 142,000 new jobs and 640,000 vacancies in these sectors over the coming years.

- At $25 \%$, computing skills will be in greatest demand. Also, computer services will be the industry most dependent on science, followed by scientific research, information and services, communications, and computers.

- Entire industries' jobs, including science, research, engineering, and technology jobs, will account for $7.8 \%$ of all jobs in the UK, equivalent to 2,525,000 jobs.

- To keep up with 2030, graduate studies must continue, particularly in basic sciences. Furthermore, graduates in science, engineering, and mathematics will be the most highly paid in the future.

- The study concludes that future jobs include computer programmers, consultants, robotics engineers, and data analysts.

The ILO (2016) carried out a study entitled "Asia in Transition: The Future of Jobs at Risk of Automation." Conducted in cooperation with the ILO Office for Employer Activities and the ILO Regional Office in Asia and the Pacific, the study topic was widely shared between 2015 and 2016. The study examines current technology and future trends in the ASEAN region and how they affect projects and workers in five primary sectors: auto parts, electricity, electronics, textile and clothing, and shoes and retail. According to many interviews and case studies, the study reached many results, perhaps the most important of which are the following.

- There are two types of jobs, including routine jobs that cannot resist automation, such as banking, printing, and machine operators, and non-routine jobs that require judgment, problem-solving, intuition, persuasion, and creativity, and thus can resist automation as such professions as doctors, lawyers, and managers do.

- Surveys show the concern of $40 \%$ of young people all over the world about job opportunities in the future, for which there is no clear strategy. Thus, East Asian countries must make strategic plans to respond to different 
labor-market requirements in the future, as $56 \%$ of existing workers in ASEAN countries face high risks of job loss and automation.

The Organization for Economic Co-operation and Development (OECD, 2017) conducted a study entitled "Going Digital: The Future of Work for Women." One of its most relevant results was that continuous digital transformation will enhance the employment of women in the labor market, along with observing that women outperform men, especially in the field of science. Also, women's jobs are less likely to be automated, primarily those requiring higher-order thinking skills. Therefore, governments must devise scientific policy-development strategies to avoid a gender gap in the future due to job automation.

In the same context, Ghada Saleh (2003) offered a study entitled "The Challenges of the Contemporary Scientific and Technological Revolution and its Impact on Obstructing Human Resources in the United Arab Emirates." The study intends to identify the challenges of the contemporary technological revolution, which hinder human resources in the United Arab Emirates. One of the most significant findings of the study was the deficiencies in human-resource development within the general development plans of the country, requiring reformulating policies related to human-resource development regarding keeping pace with modern technological developments.

Basem (2004), presented a study, entitled "The Technology Revolution and its Role in Developing Economic and International Relations," that aims to investigate the relationship between human development and gap indicators, a reality that must be dealt with through the shift toward electronic business and the use of modern technological means. The study concludes with the fact that the technological revolution has increased the world actors' interdependence, as well as the need for partnership and cooperation between different countries and institutions, especially concerning scientific research.

Through reviewing the previous studies, which have dealt in their entirety with the impact of modern technology on future jobs, we can conclude with the following.

- Most of the earlier studies investigated the impact of recent technological developments on future careers, such as the studies by McKinsey Global Institute (2017), the International Labor Organization (2016), and the Organization for Economic Cooperation and Development (OECD, 2017).

- Some previous studies include a long period of research, nearly two years or more, with the participation of many researchers, experts, and specialists, such as the McKinsey Global Institute (2017) study.

- Previous studies often are limited to predicting future jobs in general until 2030, consistent with the Saudi Vision 2030, e.g., the study of the McKinsey Global Institute (2019), Future Foresight Foundation (2019), and the Social Market Foundation (2016), which came out with many jobs expected to open by 2030, especially in science, research, engineering, and technology.

- One of these studies, by the International Labor Organization (2016) in cooperation with the International Labor Organization Office for Employer Activities and the Regional Office of the International Labor Organization in Asia and the Pacific, investigated the impact of automation on future jobs in specific countries, limiting its scope to the Association of Southeast Asian Nations (ASEAN). The study's purpose was to examine the current technology and future trends in these countries and how they affect projects and workers in five key sectors, such as the auto-parts sector, the electrical sector, the electronics sector, the textiles, clothing and shoe sector, and the retail sector.

- Few previous studies stick to examining the future of women's work in light of the digital transformation, such as the study carried out by the Organization for Economic Cooperation and Development (OECD, 2017). Most of the previous studies investigate the impact of modern technological developments on future jobs, i.e., the studies by McKinsey Global Institute (2017), the International Labor Organization (2016), and the Organization for Economic Cooperation and Development (OECD, 2017).

Accordingly, no study tries to research the topic of building academic entrepreneurial programs at Saudi universities by predicting future jobs in the context of the NEOM Project. This new project requires such a study, as well as conducting studies with experts and specialists, to come up with recommendations about future jobs that the future Saudi labor market will need.

\section{Method}

The current study used a descriptive analytical approach that depends on analyzing the actual current job picture in the KSA and determining its suitability for the Kingdom's trend toward Vision 2030. Moreover, this study focused on the new technical directions of the NEOM project, the largest KSA project to date. The Delphi method also helped to 
determine the most significant expectations for future jobs, in light of the modern technological trends of the NEOM project. This prediction emerged from the perspectives of ten experts in the field of science and technology, human resources, educational administration, and planning. The study method included the following stages.

- Define the study problem.

- Determine the suitable experts for the case.

- Select a group of experts.

- Review and investigate the literature on the topic of the current study (e.g., studies, reports, documents).

- Take advantage of the associated literature to design the current study instrument.

- Apply the Delphi method in an initial round to a preliminary sample.

- Develop the questionnaire for implementation in the pilot study (first round).

- Verify the validity and reliability of the study instrument.

- Develop the questionnaire for use in the second round, considering the results of the first-round analysis.

- Distribute the questionnaire in the second round; then, analyze the results.

- Improve the questionnaire for implementation in the third round, taking account of ideas in the second-round responses.

- Distribute the questionnaire in the third round; then, analyze the results.

- Provide a report on the results and expectations for future jobs, in light of the modern technical direction of the NEOM project.

\subsection{Study Sample}

The study participants were a sample of ten experts in the fields of science and technology, human resources, educational administration, and planning. They were intentionally chosen because they met the guarantees that successful implementation of the Delphi method requires.

\subsection{Characteristics of Study Sample}

The characteristics of the study sample focus on three demographic variables: nationality, education level, and years of experience. Table 1 illustrates them.

Table 1. Characteristics of Study Sample

\begin{tabular}{|c|c|c|c|}
\hline Variable & Category/ Characteristics & No. & $\%$ \\
\hline \multirow{2}{*}{ Nationality } & Saudi & 4 & $40 \%$ \\
\hline & Non-Saudi & 6 & $60 \%$ \\
\hline \multirow{2}{*}{ Education Level } & Bachelor & 1 & $10 \%$ \\
\hline & Master's and above & 9 & $90 \%$ \\
\hline \multirow{3}{*}{ Years of Experience } & Less than 10 years & 4 & $40 \%$ \\
\hline & 10 years or more & 6 & $60 \%$ \\
\hline & & 10 & $100 \%$ \\
\hline
\end{tabular}

\subsection{Study Instrument}

Based on the purpose of the study, the literature, and the scientific principles of using the Delphi method, the questionnaire was the most appropriate tool for this study, to collect the experts' predictions about future jobs, in light of the modern technology trends of the NEOM project for the coming ten years.

The design of the study instrument (the questionnaire) passed through some stages. First, conduct an analytical study of the current jobs in various fields, required skills, and their level in the KSA, aiming to enhance the theoretical background for this study and determine the current jobs related to the modern technology trends of the NEOM project. Seconed, design the study instrument (the questionnaire) in its initial version to conduct an exploratory round, consisting of nine open questions to identify the most significant future jobs in the KSA, in light of the nine investment sectors of the NEOM project. Next, develop the study questionnaire to conduct a pilot study, consisting of three parts. First Part included information about the purpose of the study and confidential dealing with the 
information the experts provided. Second Part involved a set of demographic questions regarding nationality, education level, and years of experience. Third Part consisted of two questions - an open-ended question on 36 future jobs, (four jobs for each investment sector) and another open question for the experts to freely express expectations of other jobs not mentioned in the question. The two questions together address the prediction of future jobs in light of the new technology trends of the NEOM project. Fourthly, conduct the pilot study with five experts (the first round) to become acquainted with the results of the application in designing the questionnaire according to the approved study method. After that, verify the validity and reliability of the study instrument and modify it in light of the results of those tests. Then, redesign it for conducting the second round. The questionnaire consisted of twenty-nine future jobs, shown in the open-ended question, and a second open question. Instead of the five-point Likert scale, the study used the triple Likert scale for the degree of expectation, as it can more accurately capture the responses of experts in their fields. Accordingly, the estimation level for averages was determined based on (2.33-3.00), (1.66-2.32), and (1.00-1.65) indicating a high, moderate, and low level of importance, respectively. Finally, reconstruct the study questionnaire after the second round, taking advantage of the results of this round, as well as the new expectations it contained along with developing the survey for application in the third round and repeat until a degree of stability in the responses of the study sample is achieved.

\subsection{Validity and Reliability}

The study questionnaire was presented to experts who are competent, experienced, and specialized, to benefit from their observations and perspectives on job titles, clarity, and suitability for particular sectors. Their views contributed to the improvement that led to the final version of the questionnaire, with the necessary adjustments to verify the content veracity.

Conducting a pilot study of five respondents and calculating the Pearson's Correlation Coefficient verified the validity of internal consistency. The pilot-study respondents were isolated from the actual study sample. For the degree of correlation, 0.40 was adopted as a minimum level of internal consistency by calculating the correlation of each job with the total degree of the investment sector to which it belongs, and the correlation of each sector with the total degree of the instrument. The nine NEOM sectors are:

- Energy and Water Sector;

- Mobility Sector;

- Biotech Sector;

- Food Sector;

- Advanced Manufacturing Sector;

- Media and Media Production;

- Entertainment Sector;

- Technological and Digital Sciences Sector;

- Living as a Foundation Sector.

Table 2 explains the Pearson Correlation Coefficients each job with the total degree of the investment sector to which it belongs. Also, table 3 presents the Pearson Correlation Coefficients of each job with the total degree of the instrument. The data of the two tables show that all correlation coefficients are statistically significant, and this indicates the validity of the internal consistency of the instrument. 
Table 2. Pearson Correlation Coefficients for Each Job to the Total Degree of Its Investment Sector

\begin{tabular}{|c|c|c|c|c|c|c|c|c|c|}
\hline \multicolumn{2}{|c|}{ Sector 1} & \multicolumn{2}{|c|}{ Sector 2} & \multicolumn{2}{|c|}{ Sector 3} & \multicolumn{2}{|c|}{ Sector 4} & \multicolumn{2}{|c|}{ Sector 5} \\
\hline $\mathrm{N}$ & $\mathrm{R}$ & $\mathrm{N}$ & $\mathrm{R}$ & $\mathrm{N}$ & $\mathrm{R}$ & $\mathrm{N}$ & $\mathrm{R}$ & $\mathrm{N}$ & $\mathrm{R}$ \\
\hline 1 & $0.719 * *$ & 4 & $0.808 * *$ & 7 & $0.577 * *$ & 11 & $0.750 * *$ & 14 & $0.586^{* *}$ \\
\hline 2 & $0.728 * *$ & 5 & $0.728 * *$ & 8 & $0.840 * *$ & 12 & $0.667 * *$ & 15 & $0.804 * *$ \\
\hline \multirow[t]{2}{*}{3} & $0.612 * *$ & 6 & $0.72 * *$ & 9 & $0.667 * *$ & 13 & $0.748 * *$ & 16 & $0.872 * *$ \\
\hline & & & & 10 & $0.729 * *$ & & & & \\
\hline \multicolumn{2}{|c|}{ Sector 6} & \multicolumn{2}{|c|}{ Sector 7} & \multicolumn{2}{|c|}{ Sector 8} & \multicolumn{2}{|c|}{ Sector 9} & & \\
\hline $\mathrm{N}$ & $\mathrm{R}$ & $\mathrm{N}$ & $\mathrm{R}$ & $\mathrm{N}$ & $\mathrm{R}$ & $\mathrm{N}$ & $\mathrm{R}$ & & \\
\hline 17 & $0.793^{* *}$ & 20 & $0.577 * *$ & 22 & $0.728 * *$ & 26 & $0.811 * *$ & & \\
\hline 18 & $0.728 * *$ & 21 & $0.545^{*}$ & 23 & $0.841 * *$ & 27 & $0.667 * *$ & & \\
\hline \multirow[t]{2}{*}{19} & $0.867 * *$ & & & 24 & $0.840 * *$ & 28 & $0.612 * *$ & & \\
\hline & & & & 25 & $0.577 * *$ & 29 & $0.840 * *$ & & \\
\hline
\end{tabular}

**. Correlation is significant at the 0.01 level (2-tailed).

*. Correlation is significant at the 0.05 level (2-tailed).

Table 3. Pearson Correlation Coefficients for each investment sector to the total degree of the instrument

\begin{tabular}{|c|c|c|c|c|c|c|c|c|c|}
\hline \multicolumn{2}{|c|}{ Sector 1} & \multicolumn{2}{|c|}{ Sector 2} & \multicolumn{2}{|c|}{ Sector 3} & \multicolumn{2}{|c|}{ Sector 4} & \multicolumn{2}{|c|}{ Sector 5} \\
\hline $\mathrm{R}$ & $0.893 * *$ & $\mathrm{R}$ & $0.719 * *$ & $\mathrm{R}$ & $0.692 * *$ & $\mathrm{R}$ & $0.841 * *$ & $\mathrm{R}$ & $0.612^{* *}$ \\
\hline \multicolumn{2}{|c|}{ Sector 6} & \multicolumn{2}{|c|}{ Sector 7} & \multicolumn{2}{|c|}{ Sector 8} & \multicolumn{2}{|c|}{ Sector 9} & & \\
\hline $\mathrm{R}$ & $540.0 * *$ & $\mathrm{R}$ & $0.951 * *$ & $\mathrm{R}$ & $0.775 * *$ & $\mathrm{R}$ & $0.628 * *$ & & \\
\hline \multicolumn{10}{|c|}{ *. Correlation is significant at the 0.05 level (2-tailed). } \\
\hline
\end{tabular}

The pilot study data was used to measure the reliability of the instrument. Cronbach's Alpha was measured to verify the consistency of the instrument by calculating the degree of stability of each sector, as well as the total stability value for all sectors. As presented in Table 4, the instrument has a large Cronbach's Alpha of 0.841. Also, the nine sectors have good and acceptable reliabilities, indicating that the tool measures the purpose for which it was prepared.

Table 4. Cronbach's Alpha for Each Sector and the Total Instrument

\begin{tabular}{cccc}
\hline Sector & Cronbach's Alpha & Sector & Cronbach's Alpha \\
\hline 1 & 0.789 & 6 & 0.767 \\
2 & 0.886 & 7 & 0.855 \\
3 & 0.985 & 8 & 0.687 \\
4 & 0.667 & 9 & 0.977 \\
5 & 0.878 & Total & 0.841 \\
\hline
\end{tabular}

\subsection{Ethical Considerations}

The confidentiality of the data was ensured, and it was not used for any cases other than the purpose for which it was collected in this study. According to the Delphi method, the study also implemented the requirement that the experts involved in the prediction did not know each other, to ensure their freedom and objectivity in expressing their opinions.

\subsection{Procedures of Data Collection}

The questionnaires were distributed in the first round to the survey sample, then retrieved. This was followed by the distribution and retrieval in the second round. A step to analyze the collected data was performed. The experts received the questionnaires in the third round, along with the second-round results, and then the questionnaires were retrieved. Again, the collected data were analyzed using the appropriate statistical methods. No further rounds occurred, as the responses had reached a level of stability. The data collection and analysis enabled the study to provide a suggested model for building academic entrepreneurial programs at Saudi universities by examining future jobs, in light of the modern technological approach of the NEOM project. 


\section{Data Analysis and Results}

This section presents the results of the study, expressing the experts' perspectives on future jobs in the Kingdom of Saudi Arabia, in light of the modern technological trends of the NEOM project. The experts agreed upon these perspectives through three scientific rounds, according to the Delphi Technique method. The results of these scientific rounds follow.

\subsection{Results of the Exploratory Round}

The Delphi Technique method was performed in an exploratory round on a survey sample of four experts, through an open questionnaire consisting of nine questions that collectively represent the nine investment sectors of the NEOM project. In this round, each expert was asked to provide an opinion on the potential future jobs to advance these sectors. The purpose of this round was to enhance the theoretical background of the study and to obtain information that helped to develop the study questionnaire. This round produced thirty-six suggested future jobs.

\subsection{Results of the First Round}

This round aimed to ensure that the study questionnaire was designed according to the Delphi method, with its specific scientific steps, and to measure its validity and reliability. Five experts participated in a pilot study, through a questionnaire consisting of two questions that, in the aggregate, represent future jobs in the Kingdom of Saudi Arabia, in light of the modern technological trends of the NEOM project. Based on this round, along with the results and recommendations the experts presented and the results of validity and reliability tests, the questionnaire was developed in its final version, consisting of twenty-nine suggested jobs that serve the nine sectors of the NEOM project.

\subsection{Results of the Second Round}

Table 5 presents the results of the field study in this round, where the suggested jobs were presented and discussed in the whole questionnaire, as well as the high, moderate, and low expectations and the added jobs in the second round, if any. The following are the results of the second round of the Delphi Technique.

Table 5. Descriptive Statistics from the Second Round of Future Jobs in the KSA in Light of the Modern Technological Trends of the NEOM Project $(n=10)$

\begin{tabular}{|c|c|c|c|c|c|}
\hline $\mathrm{N}$ & Job & $M$ & $S D$ & $\begin{array}{c}\text { Importance } \\
\text { Degree }\end{array}$ & Job Ranking \\
\hline 1 & Designer of External Hardware Support Structures & 2.50 & 0.498 & High & 16 \\
\hline 2 & Three-Dimensional Printing Specialist & 2.81 & 0.410 & High & 6 \\
\hline 3 & Researcher of Fusion Energy & 2.77 & 0.475 & High & 7 \\
\hline 4 & Mechatronics Engineer & 2.88 & 0.511 & High & 2 \\
\hline 5 & Molecular Cooking Technician & 2.23 & 0.765 & Moderate & 25 \\
\hline 6 & Physical Therapist & 2.72 & 0.476 & High & 10 \\
\hline 7 & Software Engineer & 2.87 & 0.566 & High & 3 \\
\hline 8 & Intelligent Building Engineer & 2.76 & 0.494 & High & 8 \\
\hline 9 & Engineer of Automation Organizations & 2.64 & 0.503 & High & 13 \\
\hline 10 & Digital Media Producer & 2.55 & 0.410 & High & 15 \\
\hline 11 & Floating Building Engineer & 2.04 & 0.843 & Moderate & 28 \\
\hline 12 & Information Security Specialist & 2.70 & 0.515 & High & 11 \\
\hline 13 & International Tax Consultant & 2.41 & 0.51 & High & 19 \\
\hline 14 & Digital Manufacturing Engineer & 2.67 & 0.631 & High & 12 \\
\hline 15 & Restaurant Designer & 2.19 & 0.666 & Moderate & 26 \\
\hline 16 & Engineer of Computerized Quantity Encrypted & 2.85 & 0.316 & High & 4 \\
\hline 17 & Renewable Energy Developer & 2.75 & 0.414 & High & 9 \\
\hline 18 & Digital Games Designer & 2.60 & 0.402 & High & 14 \\
\hline 19 & Specialist of Brain Reading Devices & 2.45 & 0.710 & High & 17 \\
\hline 20 & Technology Researcher of Concealment from the Naked Eye & 1.98 & 0.624 & Moderate & 29 \\
\hline 21 & Surgeon Using Technology & 2.91 & 0.438 & High & 1 \\
\hline 22 & Digital Officer & 2.28 & 0.479 & Moderate & 24 \\
\hline 23 & E-Marketing Specialist & 2.43 & 0.812 & High & 18 \\
\hline 24 & Logistics Support Expert & 2.30 & 0.983 & Moderate & 22 \\
\hline
\end{tabular}




\begin{tabular}{llcccc}
\hline 25 & Nutrition Specialist & 2.32 & 0.812 & Moderate & 21 \\
26 & Virtual Reality Technologies Designer & 2.83 & 0.565 & High & 5 \\
27 & Specialist of Solar Panels Installation & 2.39 & 0.640 & High & 20 \\
28 & Digital Archiving Specialist for Personal Life & 2.29 & 0.599 & Moderate & 23 \\
29 & Self-Immunologist & 2.14 & 0.891 & Moderate & 27 \\
& & 2.53 & 0.324 & High & \\
\hline
\end{tabular}

Averages and standard deviations of expert responses regarding the twenty-nine future jobs were calculated. Table 5 displays the averages, standard deviations, the degree of importance, and rank for each job. The importance degree of future jobs expected during the next decade in the KSA reached an average range of 1.98-2.91, and the overall mean for these jobs was 2.53 , with a standard deviation of 0.324 . According to the measure adopted in this study, the jobs proposed in its field within the nine targeted investment sectors are considered of great importance in achieving the modern technological trends of the NEOM project from the perspectives of the study experts.

As stated in Table 5, twenty jobs were suggested, consistent with the recent technological direction of the NEOM project, with a degree of high importance, as the values of the means for these jobs came with values greater than 2.32. Moreover, nine recommended jobs achieved a moderate degree of importance within an average range of 1.98-2.32. On the other hand, none of the proposed future jobs ranked at a low degree of importance in this round.

The following summarizes the study experts' expectations, in the second round, about the suggested future jobs in the KSA in light of the recent technological trends of the NEOM project:

\subsubsection{High Expectations}

Table 6 presents the experts' expectations ranked as of high importance for proposed future jobs in Saudi Arabia. The number of jobs with high-significance predictions was twenty out of twenty-nine, which Table 6 displays in descending order, according to their averages.

Table 6. High Expectations in the Second Round of the of Future Jobs in the KSA in Light of the Modern Technological Trends of the NEOM Project

\begin{tabular}{clcccc}
\hline N & \multicolumn{1}{c}{ Job } & $M$ & $S D$ & $\begin{array}{c}\text { Importance } \\
\text { Degree }\end{array}$ & $\begin{array}{c}\text { Job } \\
\text { Ranking }\end{array}$ \\
\hline 21 & Surgeon Using Technology & 2.91 & 0.438 & High & 1 \\
4 & Mechatronics Engineer & 2.88 & 0.511 & High & 2 \\
7 & Software Engineer & 2.87 & 0.566 & High & 3 \\
16 & Engineer of Computerized Quantity Encrypted & 2.85 & 0.316 & High & 4 \\
26 & Virtual Reality Technologies Designer & 2.83 & 0.565 & High & 5 \\
2 & Three-Dimensional Printing Specialist & 2.81 & 0.410 & High & 6 \\
3 & Researcher of Fusion Energy & 2.77 & 0.475 & High & 7 \\
8 & Intelligent Building Engineer & 2.76 & 0.494 & High & 8 \\
17 & Renewable Energy Developer & 2.75 & 0.414 & High & 9 \\
6 & Physical Therapist & 2.72 & 0.476 & High & 10 \\
12 & Information Security Specialist & 2.70 & 0.515 & High & 11 \\
14 & Digital Manufacturing Engineer & 2.67 & 0.631 & High & 12 \\
9 & Engineer of Automation Organizations & 2.64 & 0.503 & High & 13 \\
18 & Digital Games Designer & 2.60 & 0.402 & High & 14 \\
10 & Digital Media Producer & 2.55 & 0.410 & High & 15 \\
1 & Designer of External Hardware Support Structures & 2.50 & 0.498 & High & 16 \\
19 & Specialist of Brain Reading Devices & 2.45 & 0.710 & High & 17 \\
23 & E-Marketing Specialist & 2.43 & 0.812 & High & 18 \\
13 & International Tax Consultant & 2.41 & 0.581 & High & 19 \\
27 & Specialist of Solar Panels Installation & 2.39 & 0.640 & High & 20 \\
\hline
\end{tabular}

In general, the responses of the expert sample in this round represent high averages, ranging from 2.39 to 2.90 out of 3 , indicating a kind of agreement among the experts' perspectives on the high importance of these jobs. Job No. 21 in the questionnaire, "Surgeon Using Technology," achieved the rank of the highest degree of importance, with an average of 2.91 out of 3. Job No. 27, "Specialist of Solar Panels Installation," ranked lowest in terms of the degree of 
importance, with an average of 2.39 out of 3 . The remaining eighteen jobs covered a 0.47 range within the category of high expectations. Obviously, most of the jobs included in the second round are considered of high importance in achieving the modern technological trends of the NEOM project.

\subsubsection{Moderate Expectations}

Table 7 presents the experts' expectations for the suggested future jobs of moderate importance in Saudi Arabia, in light of the new technological direction of the NEOM project. Nine out of twenty-nine jobs reached average significance as Table 7 presents them, in descending order, according to their averages.

Table 7. Moderate Expectations in the Second Round of the Future Jobs in the KSA, in Light of the Modern Technological Trends of the NEOM Project

\begin{tabular}{clcccc}
\hline $\mathrm{N}$ & \multicolumn{1}{c}{ Job } & $M$ & $S D$ & $\begin{array}{c}\text { Importance } \\
\text { Degree }\end{array}$ & $\begin{array}{c}\text { Job } \\
\text { Ranking }\end{array}$ \\
\hline 25 & Nutrition Specialist & 2.32 & 0.812 & Moderate & 21 \\
24 & Logistics Support Expert & 2.30 & 0.983 & Moderate & 22 \\
28 & Digital Archiving Specialist for Personal Life & 2.29 & 0.599 & Moderate & 23 \\
22 & Digital Officer & 2.28 & 0.479 & Moderate & 24 \\
5 & Molecular Cooking Technician & 2.23 & 0.765 & Moderate & 25 \\
15 & Restaurant Designer & 2.19 & 0.666 & Moderate & 26 \\
29 & Self-Immunologist & 2.14 & 0.891 & Moderate & 27 \\
11 & Floating Building Engineer & 2.04 & 0.843 & Moderate & 28 \\
20 & Technology Researcher of Concealment from The Naked Eye & 1.98 & 0.624 & Moderate & 29 \\
\hline
\end{tabular}

According to Table 7 , four jobs $(25,24,28,22)$ approach the category of highest importance, with means ranging from 2.28 to 2.32. The remaining five jobs with predictions less than or equal to 2.23 include job no. 20, "Technology Researcher of Concealment from the Naked Eye," with the lowest $(M=1.98)$.

\subsubsection{Low Expectations (Excluded)}

The results of the second round of Delphi Technique rounds did not show any low expectations for any proposed job included in the questionnaire, nor did this round add any predictions in the responses to the open question. To increase the level of confidence and achieve greater consistency in the experts' predictions, all expectations of high importance, as well as the four jobs with moderate expectations close to the category of high expectations, were included when designing the study questionnaire for the third of the Delphi Technique rounds. Accordingly, the number of expectations for future jobs in the third round reached 24 .

\subsection{Results of the Third Round}

According to the Delphi method, the design of the questionnaire in the third round was based on the results obtained through the second round. The experts in that round also received the results of the second round as feedback on the expectations from that round. The results of the field study presented in the third round appear in Table 8 .

Means and standard deviations were calculated for the experts' responses to the twenty-four jobs entered in the third round. Table 8 indicates that the degree of importance of future jobs expected during the next decade in the KSA, in light of the new technological direction of the NEOM project, came with means ranging between 1.99 and 2.95, and the overall average for these jobs was 2.59 , with a standard deviation of 0.365 . According to the measure adopted in this study, the jobs proposed in the field within the nine targeted investment sectors are considered of great importance in achieving the modern technological directions of the NEOM project, from the experts' perspectives. As Table 8 shows, twenty of the proposed future jobs ranked at a high degree of significance. The average values of these jobs are higher than the upper limit of the moderate response category at 2.32. However, four of the proposed jobs obtained a moderate degree of importance within an average ranging between 1.99 and 2.22. On the other hand, none of the proposed future jobs scored a low degree of importance in this round. 
Table 8. Descriptive Statistics for the Third Round of Future Jobs in the KSA in Light of the Modern Technological Trends of the NEOM Project $(n=10)$

\begin{tabular}{|c|c|c|c|c|c|}
\hline $\mathrm{N}$ & Job & $M$ & $S D$ & $\begin{array}{l}\text { Importance } \\
\text { Degree }\end{array}$ & $\begin{array}{c}\text { Job } \\
\text { Ranking }\end{array}$ \\
\hline 21 & Surgeon Using Technology & 2.92 & 0.319 & High & 2 \\
\hline 4 & Mechatronics Engineer & 2.95 & 0.410 & High & 1 \\
\hline 7 & Software Engineer & 2.90 & 0.566 & High & 3 \\
\hline 16 & Engineer of Computerized Quantity Encrypted & 2.88 & 0.343 & High & 4 \\
\hline 26 & Virtual Reality Technologies Designer & 2.86 & 0.786 & High & 5 \\
\hline 2 & Three-Dimensional Printing Specialist & 2.78 & 0.565 & High & 6 \\
\hline 3 & Researcher of Fusion Energy & 2.57 & 0.768 & High & 15 \\
\hline 8 & Intelligent Building Engineer & 2.77 & 0.475 & High & 7 \\
\hline 17 & Renewable Energy Developer & 2.74 & 0.514 & High & 9 \\
\hline 6 & Physical Therapist & 2.65 & 0.703 & High & 12 \\
\hline 12 & Information Security Specialist & 2.77 & 0.475 & High & 8 \\
\hline 14 & Digital Manufacturing Engineer & 2.70 & 0.341 & High & 10 \\
\hline 9 & Engineer of Automation Organizations & 2.60 & 0.477 & High & 13 \\
\hline 18 & Digital Games Designer & 2.69 & 0.322 & High & 11 \\
\hline 10 & Digital Media Producer & 2.58 & 0.506 & High & 14 \\
\hline 1 & Designer of External Hardware Support Structures & 2.57 & 0.311 & High & 16 \\
\hline 19 & Specialist of Brain Reading Devices & 2.50 & 0.763 & High & 17 \\
\hline 23 & E-Marketing Specialist & 2.44 & 0.666 & High & 18 \\
\hline 13 & International Tax Consultant & 2.43 & 0.498 & High & 19 \\
\hline 27 & Specialist of Solar Panels Installation & 2.40 & 0.557 & High & 20 \\
\hline 25 & Nutrition Specialist & 2.10 & 0.657 & Moderate & 22 \\
\hline 24 & Logistics Support Expert & 2.22 & 0.933 & Moderate & 21 \\
\hline 28 & Digital Archiving Specialist for Personal Life & 2.08 & 0.432 & Moderate & 23 \\
\hline 22 & Digital Officer & 1.99 & 0.637 & Moderate & 24 \\
\hline & Total & 2.59 & 0.365 & High & \\
\hline
\end{tabular}

All jobs that received high or moderate estimates in the second round did not change in the third round, except for a slight difference in the degree of importance of only certain jobs. This is an indication of response stability in the experts' assessments of job importance and its relevance to the new technological trends of the NEOM project. Following is a summary of the experts' expectations in the third round regarding the recommended future jobs in the $\mathrm{KSA}$, in light of the modern technological direction of the NEOM project:

\subsubsection{High Expectations}

Table 9 presents the experts' expectations of a high degree of importance of proposed future jobs in Saudi Arabia, in light of the recent technological direction of the NEOM project. The number of jobs with high expectations was 20 out of 24. Table 9 shows these jobs in descending order, according to their averages.

Overall, the responses of the experts in this round represent a high estimate and mostly agree with their ratings in the second round, with averages ranging between 2.40 and 2.95 out of 3 . This result indicates agreement among the experts on the great importance of these jobs in achieving the technological orientation of the NEOM project.

According to the results, Job No. 4 in the questionnaire, "Mechatronics Engineer," achieved the highest expectation in terms of the degree of importance, with an average of 2.95 out of 3. Job No. 27, "Specialist of Solar Panels Installation," reached the lowest expectation in terms of the degree of importance, with an average of 2.40 out of 3. The remaining eighteen jobs fell within a 0.49 range in the category of high expectations. These results make evident that the experts consider most of the jobs included in the third round to be of high importance, in line with the new technological direction of the NEOM project. 
Table 9. High Expectations in the Third Round of the Future Jobs in the KSA, in Light of the Modern Technological Trends of the NEOM Project

\begin{tabular}{clcccc}
\hline N Job & \multicolumn{1}{c}{$M$} & $S D$ & $\begin{array}{c}\text { Importance } \\
\text { Degree }\end{array}$ & $\begin{array}{c}\text { Job } \\
\text { Ranking }\end{array}$ \\
\hline 4 & Mechatronics Engineer & 2.95 & 0.410 & High & 1 \\
21 & Surgeon Using Technology & 2.92 & 0.319 & High & 2 \\
7 & Software Engineer & 2.90 & 0.566 & High & 3 \\
16 & Engineer of Computerized Quantity Encrypted & 2.88 & 0.343 & High & 4 \\
26 & Virtual Reality Technologies Designer & 2.86 & 0.786 & High & 5 \\
2 & Three-Dimensional Printing Specialist & 2.78 & 0.565 & High & 6 \\
8 & Intelligent Building Engineer & 2.77 & 0.475 & High & 7 \\
12 & Information Security Specialist & 2.77 & 0.475 & High & 8 \\
17 & Renewable Energy Developer & 2.74 & 0.514 & High & 9 \\
14 & Digital Manufacturing Engineer & 2.70 & 0.341 & High & 10 \\
18 & Digital Games Designer & 2.69 & 0.322 & High & 11 \\
6 & Physical Therapist & 2.65 & 0.703 & High & 12 \\
9 & Engineer of Automation Organizations & 2.60 & 0.477 & High & 13 \\
10 & Digital Media Producer & 2.58 & 0.506 & High & 14 \\
3 & Researcher of Fusion Energy & 2.57 & 0.768 & High & 15 \\
1 & Designer of External Hardware Support Structures & 2.57 & 0.768 & High & 16 \\
19 & Specialist of Brain Reading Devices & 2.50 & 0.763 & High & 17 \\
23 & E-Marketing Specialist & 2.44 & 0.666 & High & 18 \\
13 & International Tax Consultant & 2.43 & 0.498 & High & 19 \\
27 & Specialist of Solar Panels Installation & 2.40 & 0.557 & High & 20 \\
\hline
\end{tabular}

10.4.2 Modreate Expectations

Table 10 shows the experts' expectations of moderately important future jobs (4 out of 24).

Table 10. Moderate Expectations in the Third Round of the Future Jobs in the KSA, in Light of the Modern Technological Trends of the NEOM Project

\begin{tabular}{llrrrr}
\hline \multicolumn{1}{c}{ Job } & $M$ & $S D$ & $\begin{array}{c}\text { Importance } \\
\text { Degree }\end{array}$ & Job Ranking \\
\hline 24 & Logistics Support Expert & 2.22 & 0.933 & Moderate & 21 \\
25 & Nutrition Specialist & 2.10 & 0.657 & Moderate & 22 \\
28 & Digital Archiving Specialist for Personal Life & 2.08 & 0.432 & Moderate & 23 \\
22 & Digital Officer & 1.99 & 0.637 & Moderate & 24 \\
\hline
\end{tabular}

Four jobs reached averages ranging from 1.99 to 2.22, and they record a lower mean than some other jobs that appeared in the second round. Thus, they are excluded from entering the third round and from the list of future jobs in the final scenario.

\subsubsection{Low Expectations (Excluded)}

The results of the third round of the Delphi Technique round did not show any low expectations for any proposed job included in the questionnaire. Also, this round did not result in adding any expectations for other new jobs within the response to the open question.

\subsection{Results of the Third Round}

The current study included a null hypothesis that stated:

H0: There are no statistically significant differences at $(\alpha \leq 0.05)$ between the averages of the second and third rounds in the perceptions of the study-sample respondents regarding their estimations of the degree of future job importance, in light of the recent technological direction of the NEOM project.

To test this hypothesis, a T-Test was utilized to study the differences between the averages of the expert-sample responses in the second and third rounds, regarding future jobs in the KSA, at the level of significance $(\alpha \leq 0.05)$, as Table 11 shows. 
Table 11. T- Test Results of the Differences between the Mean Responses of Experts in the Second and Third Rounds

\begin{tabular}{|c|c|c|c|c|c|c|c|c|}
\hline \multirow{2}{*}{$\begin{array}{l}\text { Job Ranking } \\
\text { according to } \\
\text { third round }\end{array}$} & \multicolumn{3}{|c|}{ Second Round } & \multicolumn{3}{|c|}{ Third Round } & \multirow[b]{2}{*}{$t$} & \multirow{2}{*}{$\begin{array}{c}\text { Sig. } \\
\text { (2-tailed) }\end{array}$} \\
\hline & M & SD & $\begin{array}{l}\text { Degree of } \\
\text { importance }\end{array}$ & M & SD & $\begin{array}{l}\text { Degree of } \\
\text { importance }\end{array}$ & & \\
\hline 1 & 2.88 & 0.511 & High & 2.95 & 0.410 & High & -0.546 & 0.748 \\
\hline 2 & 2.91 & 0.438 & High & 2.92 & 0.319 & High & -0.112 & 0.768 \\
\hline 3 & 2.87 & 0.566 & High & 2.90 & 0.566 & High & -0.435 & 0.626 \\
\hline 4 & 2.85 & 0.316 & High & 2.88 & 0.343 & High & -0.324 & 0.657 \\
\hline 5 & 2.83 & 0.565 & High & 2.86 & 0.786 & High & -0.313 & 0.984 \\
\hline 6 & 2.81 & 0.410 & High & 2.78 & 0.565 & High & 0.231 & 0.657 \\
\hline 7 & 2.76 & 0.494 & High & 2.77 & 0.475 & High & -0.319 & 0.632 \\
\hline 8 & 2.70 & 0.515 & High & 2.77 & 0.475 & High & -0.513 & 0.776 \\
\hline 9 & 2.75 & 0.414 & High & 2.74 & 0.514 & High & 0.254 & 0.665 \\
\hline 10 & 2.67 & 0.631 & High & 2.70 & 0.341 & High & -0.223 & 0.874 \\
\hline 11 & 2.60 & 0.402 & High & 2.69 & 0.322 & High & -0.533 & 0.558 \\
\hline 12 & 2.72 & 0.476 & High & 2.65 & 0.703 & High & 0.334 & 0.732 \\
\hline 13 & 2.64 & 0.503 & High & 2.60 & 0.477 & High & 0.132 & 0.876 \\
\hline 14 & 2.55 & 0.410 & High & 2.58 & 0.506 & High & -0.632 & 0.978 \\
\hline 15 & 2.77 & 0.475 & High & 2.57 & 0.768 & High & 0.524 & 0.675 \\
\hline 16 & 2.50 & 0.498 & High & 2.57 & 0.768 & High & -0.357 & 0.641 \\
\hline 17 & 2.45 & 0.710 & High & 2.50 & 0.763 & High & -0.239 & 0.882 \\
\hline 18 & 2.43 & 0.812 & High & 2.44 & 0.666 & High & -0.132 & 0.669 \\
\hline 19 & 2.41 & 0.581 & High & 2.43 & 0.498 & High & -0.327 & 0.992 \\
\hline 20 & 2.39 & 0.640 & High & 2.40 & 0.557 & High & -0.117 & 0.586 \\
\hline Total & 2.67 & 0.209 & High & 2.69 & 0.367 & High & -0.198 & 0.681 \\
\hline
\end{tabular}

Table 11clearly shows that all the significance level values were statistically insignificant for all jobs, which means that there are no statistically significant differences in the perceptions of experts at the significance level $(\alpha \leq 0.05)$ between the averages of the second and third rounds. The experts' responses reflect consistency and stability, which supports stopping at this number of rounds, according to the approved study method.

\section{Discussion}

Saudi universities should make much greater efforts to develop entrepreneurial programs, through making predictive studies of future jobs and establishing new entrepreneurial academic programs that meet the needs for those jobs. Debates and predictions persist about what future jobs are and whether automation will eliminate jobs or create new ones. Studies have mostly focused on the impact of technology and automation on the future of jobs (Arntz et al., 2016; Frey and Osborne, 2017; McKinsey, 2017; PwC, 2017; Foundation for Young Australians FYA, 2017; Future Foresight Foundation, 2019; McKinsey, 2019). Hence, through three scientific rounds following the initial preliminary round, the current study reached the expected perception of future jobs in the Kingdom of Saudi Arabia, in the light of the new tech direction of the NEOM project. Twenty future jobs obtained degrees of high importance. According to the experts' point of view, the averages for these jobs ranged from 2.40 to 2.95 out of 3 . Table 12 represents these jobs according to their respective degrees of importance: 
Table 12. Top 20 Important Jobs in the Future

\begin{tabular}{cl}
\hline Job Ranking & Mechatronics Engineer \\
\hline 1 & Surgeon Using Technology \\
3 & Software Engineer \\
4 & Engineer of Computerized Quantity Encrypted \\
5 & Virtual Reality Technologies Designer \\
6 & Three-Dimensional Printing Specialist \\
7 & Intelligent Building Engineer \\
8 & Information Security Specialist \\
9 & Renewable Energy Developer \\
10 & Digital Manufacturing Engineer \\
11 & Digital Games Designer \\
12 & Physical Therapist \\
13 & Engineer of Automation Organizations \\
14 & Digital Media Producer \\
15 & Researcher of Fusion Energy \\
16 & Designer of External Hardware Support Structures \\
17 & Specialist of Brain Reading Devices \\
18 & E-Marketing Specialist \\
19 & International Tax Consultant \\
20 & Specialist of Solar Panels Installation. \\
\hline
\end{tabular}

According to the Pennsylvania Department of Labor and Industry and Future Foresight Foundation, Mechatronics Engineering is recognized as a "high-priority" job in great demand for the future (California University of Pennsylvania, 2019; Future Foresight Foundation, 2019; OECD, 2019). This fact aligned with the result of the current study, where the "Mechatronics Engineer" job reached the highest rank of jobs that experts predicted would be needed in the future. "Surgeon Using Technology" is a future job that can increase the level of precision and efficiency in surgeries in a way never observed before (TMF, 2017), aligning with the second-highest-rated job in the current study. Therefore, surgeons should develop their skills in technology to enable them to cope with the tremendous advances in the medical tech field (TMF, 2017).

According to a study conducted by Evans Data Corporation (EDC), the demand for software developers' jobs will increase to 27.7 million by 2030 (EDC, 2018). In the same context, the U.S. Bureau of Labor Statistics (BLS) (2019) indicates that between 2016 and 2026, the number of software engineers' jobs is anticipated to rise at a rate of $24 \%$ higher than any other job, which agrees with the result of this study that shows the Software Engineer job reaching the rank of third-most-important job required in the future, from the study experts' point of view. As solar technology grows and new uses for solar power are determined, future jobs in solar energy will continue to grow and develop (BLS, 2011).

Many studies have also predicted a range of future jobs and their results consistent with the current study. For example, in recent years, the application of Virtual Reality technology in our lives has significantly increased. This technology and its aspects are necessary in many future jobs, such as Software Designer and 3D Specialists (Tripathy, 2019; Cognizant's Center for the Future of Work, 2019). Regarding the field of engineering and its modern concept, Jolly and Lamarque (2011) mention that society and its engineers must search for solutions to the best energy management. This can be achieved through the use of renewable sources of energy and adoption of intelligent building methods; automation is attracting the attention of many individuals who are interested in this area. This recent trend in the field of engineering is consistent with many future jobs mentioned in this study, such as renewable energy developers and intelligent building and automation organizations engineers.

Regarding the digital field, Wellener, Dollar, and Manolian (2020) develop a series of personas that describe what jobs in 2025 look like in the digital era, particularly in the manufacturing field, from their point of view. They conclude that digital transformation and the Fourth Industrial Revolution will redefine manufacturing jobs of the future, with technologies such as artificial intelligence, advanced robotics, cognitive automation, advanced analytics, and the Internet of Things. This aligns with findings of the current study, where the digital field is one of the most significant fields for future jobs, such as digital manufacturing engineer, digital games designer, and digital media producer. 
The current study also mentions Fusion Energy as another future job area. It is a potential safe source that uses the power of the sun and stars and has attracted the attention of scientists as a promising field, with many future jobs. The International Atomic Energy Agency (2018) also describes Fusion Energy as future energy, and despite its potential advantages, it is a complex and challenging field. Cognizant's Center for the Future of Work (2019) provides a concentrated list of 21 future jobs related to marketing scope; one of these jobs is Micro-Interaction Marketing Specialist, which agrees with a result of the current study. Also, they present other future jobs that the current study does not mention, such as Algorithm Bias Auditor, Mood and Empathy Manager, Sixth Sense Analyst, Simulation Assistant, and Head of Bot Creative.

Other studies also provide a range of future jobs not mentioned in the current study. For instance, Future Foresight Foundation (2019) reveals that among the numerous significant jobs of the future (by 2040) are the jobs related to piloting drones, personal health experts, cryptocurrencies, space and space mining, and smart pipeline (Hyperloop) systems. As the population ages, jobs related to older people will be in high demand, such as memory augmentation surgeons (International Experts and Local Economic Development Agencies - ILS LEDA, 2013). Other future jobs will come from nanotechnology and biotechnology, such as body-part maker, nano-medic, bio-informationist, and geomicrobiologist.

\section{Conclusion}

What worries most young people today is finding a job in the future. Thus, their frequent question is about the required specializations that will guarantee them those jobs. Hence, universities are essential, and their responsibility is to guide students and update their programs to suit modern trends, especially technological ones. While traditional jobs are no longer sufficient, the academics, officials, and employers must work together to predict future positions until the gap between education outcomes and labor-market requirements is bridged. Recently, several investment projects have emerged related to the future directions of the Saudi National Vision 2030, and such projects will require many jobs that did not exist before. Since the NEOM project is considered one of the most important of these massive projects, the current study concludes what the top twenty future jobs will be, in light of this enormous project. Furthermore, the results of the present study did not result in a statistically significant difference between the views of the study experts on the importance of these functions, according to Delphi Technique multiple rounds.

\section{Recomendations}

The study's results lead to the following recommendations.

1. Direct Saudi universities to develop academic programs that meet the needs of the NEOM project in the disciplines of Mechatronics Engineering, Surgery Using Technology, and Software Engineering.

2. Build academic programs in the light of specific learning outcomes that ensure graduates can acquire the necessary entrepreneurial skills, especially in disciplines of Computerized Quantity Encrypted Engineering, Virtual Reality Technologies Designing, and Three-Dimensional Printing Specializing.

3. Reduce the acceptance of traditional academic programs that do not match the future requirements of the labor market and the Saudi 2030 Vision initiatives and projects, such as the NEOM project, and locate these seats in more closely related programs.

4. Develop all programs to be entrepreneurial in various universities and colleges, toward the new and expected technical trends in the labor market and all promising sectors of investment, such as the NEOM project.

\section{References}

Acker, O. (2015). The digital future of creative Europe. Strategyand.pwc.com. Retrieved from https://www.strategyand.pwc.com/media/file/The-digital-future-of-creative-Europe-2015.pdf

Ah Kim, S., Yun Ryoo, H., \& Joo Ahn, H. (2017). Student customized creative education model based on open innovation. Journal of Open Innovation: Technology, Market, and Complexity, 3(1), 6. https://doi.org/10.1186/s40852-016-0051-y

Al Barqawi, A. (2017). This is why the NEOM project was named. Retrieved from https://sabq.org/wS2szk

Al-Maiman, M. (2012). Developing training programs to meet the needs of the labor market and address the problem of unemployment in the Kingdom of Saudi Arabia. International Conference on the Integration of Education Outputs with the Labor Market in the Public and Private Sector, Jordan, 25-28/3/2012. 
Al-Mohandes, A. (2016). The Kingdom's Vision 2030 and comprehensive development. Retrieved from http://www.alriyadh.com/1151096

Alzahrani, M. (2018). Appropriateness of the King Saud University Art Education Program's outputs for the needs of the Saudi labor market in accordance with Vision 2030. Journal of Educational Sciences, 30(3), 427-451.

Aref, A., Hegazy, A., \& Abdel-Hamid, M. (2108). The quality of learning outcomes in Saudi universities and their role in meeting the requirements of the Saudi labor market, in accordance with Vision 2030. Journal of Scientific Research in Education, 19, 683-741.

Arntz, M., Gregory, T., \& Zierahn, U. (2016). The risk of automation for jobs in OECD countries: A comparative analysis. Tech. Rep. 189, OECD Social, Employment and Migration Working Papers.

Bakhshi, H., Downing, J. M., Osborne, M. A., \& Schneider, P. (2017). The future of skills: Employment in 2030. Pearson.

Basem, G. (2004). The contemporary technological revolution and its role in developing economic relations. Unpublished Master's Thesis, Tishreen University, Faculty of Economics, Syrian Arab Republic.

Bostrom, N. (2007). Technological Revolutions: Ethics and Policy in the Dark. In N. M. D. S. Cameron and M. E. Mitchell (Eds.), Nanoscale: Issues and Perspectives for the Nano Century, (John Wiley).

Brain, M. (2013). "Robotic Nation FAQ," on Marshall Brain's website. Retrieved from http://marshallbrain.com/robotic-faq.htm.

Byun, C. G., Sung, C. S., Park, J. Y., \& Choi, D. S. (2018). A study on the effectiveness of entrepreneurship education programs in higher education institutions: A case study of Korean graduate programs. Journal of Open Innovation: Technology, Market, and Complexity, 4(3), 26. https://doi.org/10.3390/joitmc4030026.

California University of Pennsylvania (2017). What can you do with a mechatronics degree. Retrieved from https://www.calu.edu/academics/undergraduate/bachelors/mechatronics-engineering-technology/what-can-youdo-with-a-mechatronics-degree.aspx

Cognizant's Center for the Future of Work. (2019). 21 Marketing jobs of the future: A Guide to getting and staying employed- in marketing- for the next 10 years. Retrieved from http://www.marketersbyadlatina.com/uploads/pdf/-2237-21-Marketing-Jobs-of-the-future.pdf

Crawford, M. (2017). Advanced Manufacturing Will Drive U.S. Economic Engine - Area Development. Area Development. Retrieved from http://www.areadevelopment.com/EconomicsGovernmentPolicy/Summer2012/Advanced-Manufacturing-drives -USA-economic-engine-255422.shtml

Damanhoury. H. (2013). Reasons for higher education outcomes not being matched to the requirements of the Saudi labor market. King Abdulaziz University Journal: Economics and Management, 27(1), 277-286.

Dell EMC. (2016). What it means for KSA future ready for vision 2030. Retrieved from $\mathrm{http}: / / \mathrm{emeablog} . \mathrm{emc} . \mathrm{com} / \mathrm{sa} / \mathrm{dell}-\mathrm{emc}-\mathrm{merger}-\mathrm{means}$-ksa-future-ready-vision-2030/

DU Press. (2017). Making the future of mobility work: How the new transportation ecosystem could reshape jobs and employment. Retrieved from https://dupress.deloitte.com/dup-us-en/deloitte-review/issue-21/transportation-ecosystem-future-of-mobility-res haping-work.html

Evans Data Corporation (EDC). (2018). Developer population growth shifts toward China, India and emerging countries. Retrieved from https://evansdata.com/press/viewRelease.php?pressID=268

Foundation for Young Australians (FYA) (2017). The new basics: Big data reveals the skills young people need for the new work order. Retrieved from http://www.fya.org.au/wp-content/uploads/2016/04/The-New-Basics_Web_Final.pdf

Frey, C. B., \& Osborne, M. A. (2017). The future of employment: How susceptible are jobs to computerization? Technological Forecasting and Social Change, 114, 254-280. https://doi.org/10.1016/j.techfore.2016.08.019

Ghada, S. (2003). The challenges of the contemporary scientific and technological revolution and its impact on obstructing human resources in the United Arab Emirates (Unpublished Master Thesis). Ain Shams University, Faculty of Commerce, Egypt.

He, L., Standen, P., \& Coetzer, A. (2017). The perceived personal characteristics of entrepreneurial leaders. Small 
Enterprise Research, 24(2), 97-119. https://doi.org/10.1080/13215906.2017.1334225

International Experts and Local Economic Development Agencies (ILS LEDA). (2013). Most popular future jobs of 2030 -Elaboration from an article of Italian magazine "Panorama". Retrieved from http://www.ilsleda.org/usr_files/documents/paper_highlights-aug2013-best_jobs_2030_238456.pdf

International Labour Organization (ILO). (2016). ASEAN in transformation: The future of jobs at risk of automation. Retrieved from http://www.ilo.org/public/english/dialogue/actemp/downloads/publications/2016/asean_in_transf_2016_r2_futu re.pdf

Jolly, A. M., Léger, C., \& Lamarque, G. (2011, September). "Smart building": A new concept of engineering education curriculum. World Engineers' Convention, Sep 2011, Geneva, Switzerland.

Kaeser, J. (2017). Future Investment Initiative. Retrieved from http://futureinvestmentinitiative.com/ar/home

Kent State University. (2017). Why Digital Sciences? Retrieved from https://www.kent.edu/dsci/major-why-dsci

Lagards, Ch. (2017). Future Investment Initiative. Retrieved from http://futureinvestmentinitiative.com/ar/home

Lan, P., \& Young, S. (1996). International Technology Transfer Examined at Technology Component Level: A Case Study in China. Technovation, 16(6), 169-225. https://doi.org/10.1016/0166-4972(96)00005-3.

McKinsey Global Institute (MGI). (2017). A future that works: Automation, employment and productivity. Retrieved from https://www.mckinsey.com/mgi/overview

McKinsey Global Institute (MGI). (2018). The future of jobs in the middle east. Retrieved from https://www.mckinsey.com/ /media/mckinsey/featured $\% 20$ insights/middle $\% 20$ east $\% 20$ and $\% 20$ africa/are $\% 20 \mathrm{~m}$ iddle $\% 20$ east $\% 20$ workers $\% 20$ ready $\% 20$ for $\% 20$ the $\% 20$ impact $\% 20$ of $\% 20$ automation/the-future-of-jobs-in-themiddle-east.ashx

McKinsey Global Institute (MGI). (2019). The future of work in America People and places, today and tomorrow. Retrieved from https://www.mckinsey.com/featured-insights/future-of-work/the-future-of-work-in-america-people-and-places-t oday-and-tomorrow

National Bioscience Report Shows Industry Creating Jobs and Driving Innovation - BIO. (2017). BIO. Retrieved from

https://www.bio.org/press-release/national-bioscience-report-shows-industry-creating-jobs-and-driving-innovati on

Neom. (2017). Discover Neom. Retrieved 30 October, 2017 from http://discoverneom.com/

OECD (2017). "Going Digital: The Future of Work for Women", Policy Brief on The Future of Work, OECD Publishing, Paris. Retrieved http://www.oecd.org/employment/Going-Digitalthe-Future-of-Work-for-Women.pdf

OECD. (2019). OECD employment outlook 2019: The future of work. OECD Publishing. Retrieved from https://www.oecd-ilibrary.org/sites/ef00d169-en/index.html?itemId=/content/component/ef00d169-en

Pistono, F. (2014). Robots Will Steal Your Job but that's OK: How to Survive the Economic Collapse and Be Happy. (Lexington, KY: CreateSpace), Kindle edition, chap. 9.

Pompa, C. (2015). Jobs for the Future. Overseas Development Institute. Retrieved from https://youtheconomicopportunities.org/sites/default/files/uploads/resource/ODI-JobsfortheFuture.pdf

PwC (2017). Consumer spending prospects and the impact of automation on jobs. UK Economic Outlook, March. Retrieved from https://www.pwc.co.uk/economic-services/ukeo/pwc-uk-economic-outlook-full-report-march-2017-v2.pdf

PwC. (2017). Consumer spending prospects and the impact of automation on jobs. UK Economic Outlook, March.

PwC. (2020). The power to perform: Human capital 2020 and beyond. Retrieved from https://www.pwc.com/gr/en/publications/assets/the-power-to-perform-human-capital-2020-and-beyond.pdf

Riyadh Economic Forum. (2020, January 21- 23). Future Jobs in The Kingdom of Saudi Arabia [Online forum post]. Riyadh Economic Forum. Retrieved from http://riyadhef.com/

Saudi Press Agency. (2016). Saudi vision 2030. Retrieved from http://www.vision2030.gov.sa/ 
Schwab, K. (2017). The Fourth Industrial Revolution. London, UK: Crown Business.

Smith, H. (2017). There are more jobs in renewable energy than in oil, gas, and coal combined. Grist. Retrieved from http://grist.org/business-technology/there-are-more-jobs-in-renewable-energy-than-in-oil-gas-and-coal-combine d

The International Atomic Energy Agency. (2018). Fusion energy in the 21st century: status and the way forward. Retrieved from https://www.iaea.org/newscenter/news/fusion-energy-in-the-21st-century-status-and-the-way-forward

The Medical Futurist (TMF). (2017). The Technological Future of Surgery. Retrieved from https://medicalfuturist.com/the-technological-future-of-surgery/

The Social Market Foundation (SMF) (2016). Job of the Future. SMF Publishing, UK. Retrieved from https:/www.edfenergy.com/sites/default/files/jobs-of-the-future.pdf

Tripathy, P. (2019). Future Skills and Jobs: 5 emerging careers in Augmented Reality (AR) and Virtual Reality (VR). Retrieved

from https://www.nationalskillsnetwork.in/5-emerging-careers-in-augmented-reality-ar-and-virtual-reality-vr/

Ugal, D. B., \& Betiang, P. A. (2009). Challenges for developing human capital in Nigeria: Global-local connection. Retrieved from http://ssrn.com/abstract=1513945

US Bureau of Labor Statistics. (2011). Careers in Solar Power. Retrieved from https://www.bls.gov/green/solar_power/\#footnote1

US Bureau of Labor Statistics. (2019). Occupational Outlook Handbook, Software Developers. Retrieved from https:/www.bls.gov/ooh/computer-and-information-technology/software-developers.htm

Valerio, A., Parton, B., \& Robb, A. (2014). Entrepreneurship education and training programs around the world: dimensions for success. The World Bank. https://doi.org/10.1596/978-1-4648-0202-7

Vardy, M. (2017). How Technology is Changing the Restaurant Industry. Retrieved from https://thenextweb.com/insider/2012/09/22/how-technology-changing-restaurant-industry

Walter, S. G., \& Block, J. H. (2016). Outcomes of entrepreneurship education: An institutional perspective. Journal of Business Venturing, 31(2), 216-233. https://doi.org/10.1016/j.jbusvent.2015.10.003.

Water Industry Asset Management Conference. (2017). 3 key takeaways from the 2017 Water Industry Asset Management Conference. Retrieved from https://www.matchtech.com/2017-water-industry-conference

Wellener, P., Dollar, B., \& Manolian, H. (2020). The future of work in manufacturing: What will jobs look like in the digital era? from https:/www2.deloitte.com/us/en/insights/industry/manufacturing/future-of-work-manufacturing-jobs-in-digitalera.html

West, D. (2017). How technology is changing manufacturing. Brookings. Retrieved from https://www.brookings.edu/blog/techtank/2016/06/02/how-technology-is-changing-manufacturing

Xi, G., Block, J., Lasch, F., Robert, F., \& Thurik, R. (2018). Work experience from paid employment and entry mode to entrepreneurship: Business takeover versus new venture start-up. Entrepreneurship Review, 17(2), 91-112. https://doi.org/10.3917/entre.172.0091

Xu, M., David, J. M., \& Kim, S. H. (2018). The fourth industrial revolution: opportunities and challenges. International journal of financial research, 9(2), 90-95. https://doi.org/10.5430/ijfr.v9n2p90

\section{Copyrights}

Copyright for this article is retained by the author(s), with first publication rights granted to the journal.

This is an open-access article distributed under the terms and conditions of the Creative Commons Attribution license (http://creativecommons.org/licenses/by/4.0/). 